\title{
AVALANCHE WEATHER FORECASTING AT THE NORTHWEST AVALANCHE CENTER, SEATTLE, WASHINGTON, U.S.A.
}

\author{
By S.A. Ferguson, M.B. Moore, R.T. Marriott, and P. Speers-Hayes \\ (Northwest Avalanche Center, Box C-15700, Seattle, Washington 98115, U.S.A.)
}

\begin{abstract}
Since its inception in 1975, the Northwest Avalanche Center (NWAC) has developed and produced micro- and mesoscale weather forecasts to support avalanche forecast and control needs for the Olympic and Cascades Mountains of Washington and Oregon, U.S.A. This paper describes NWAC's array of data, observational results, and analytical techniques that make "avalanche weather" forecasting possible. In addition, NWAC's operational program and the general terrain and climate of the area are described. A sample forecast is also included.
\end{abstract}

\section{INTRODUCTION}

Over $80 \%$ of all avalanches within the mountains of the north-western United States are storm related (Fox, unpublished; Moore, unpublished). This close relationship between snow stability and weather conditions intimately ties avalanche forecasts to the local weather forecast. Thus, from its inception in 1975, the Northwest Avalanche Center (NWAC) has emphasized the development and operational production of micro-* and mesoscale weather forecasts for the surrounding mountains. Today, this program continues to refine site- and time-specific mountain weather forecasts that provide advanced warning for avalanche-producing storms.

Because the frequent and dramatic shifts in inclement weather that are common in a mountain environment can change snow-pack stability within minutes, advance warning is a vital part of avalanche-hazard mitigation. For this reason, NWAC avalanche weather forecasts are used by a variety of groups and individuals. For example, state and local avalanche-control personnel use the forecasts to plan their control methods that protect developed ski areas and highways. The National Park and Forest Services and State Parks use avalanche weather forecasts to advise visitors better on expected hazards. In addition, State highway crews use NWAC products to plan maintenance schedules and local ski schools, clubs, and guide services use the avalanche weather forecast to help avoid impending hazards.

The NWAC operation is continually evolving to develop and incorporate state-of-the-art forecasting methodology, data collection, and analysis techniques. To support these activities, NWAC forecasters have acquired extensive experience in developing and utilizing an increasingly sophisticated and site-intensive data network. This data network has allowed NWAC forecasters to describe and predict heretofore little-known phenomena like topographically forced convergence zones and pressure-induced flows that cause rapid changes in freezing levels.

NWAC's program of avalanche weather forecasting is unique in North America. There is no other program that offers such a consistent and intensive forecast of winter weather phenomena. The National Weather Service zone forecasts are general statements about expected weather over a large region. Their fire weather forecasts are numerical only during the fire season (typically May through October).

\footnotetext{
* For this purpose, microscale refers to the area of $1-10 \mathrm{~km}^{2}$ surrounding observation sites.
}

Some privately funded meteorological services are now beginning to offer site-specific mountain-weather forecasts but have yet to reach the scope and depth of currently available NWAC products. Therefore, it is hoped that the observations and analytic techniques described in this paper will provide a fundamental contribution to mountain-weather forecasting, not only for mountains of Washington and Oregon but for other alpine areas as well.

The following will explain NWAC's development and use of site- and time-specific mountain weather forecasts. First, the terrain and climate of the Pacific Northwest Mountains and some of the associated weather forecasting problems are described. Next, the data network and several analytical methods are shown. Finally, a sample forecast and dissemination procedures are described.

\section{AVALANCHE TERRAIN AND CLIMATOLOGY}

The forecast region covers over $50000 \mathrm{~km}^{2}$ of mountainous terrain within two primary ranges, the Olympic Mountains and Cascade Mountains of Washington and Oregon (Fig. 1). The Olympic Mountains are a circular massif, approximately $80 \mathrm{~km}$ in diameter, located on the Olympic Peninsula of Washington. The Cascade Mountains are a north-south oriented range approximately $200 \mathrm{~km}$ east of the Pacific coast. The $100 \mathrm{~km}$ wide range stretches the entire length of the forecast region and is intersected by several east-west oriented passes.

Major volcanism and uplift in this region has caused a dramatic rise in terrain from sea-level to about $2100 \mathrm{~m}$. Volcanic "islands" further rise $1000-2000 \mathrm{~m}$ above the mean crestline. In addition, substantial glaciation and water erosion has sculpted steep and dramatic slopes with many tortuous valleys and drainages in addition to the broad, cross-secting passes. This complex terrain significantly modifies incoming winds and associated weather throughout the Olympic and Cascade Mountains.

Daily forecasts are prepared for areas between Mount Hood to the south and the Canadian border to the north. Special forecasts are issued for Crater Lake National Park in Oregon and Whistler Mountain in British Columbia.

The following describes major topographic features that relate to avalanche terrain and associated weather.

\section{Elevation}

Most avalanche starting zones within the Cascade and Olympic Mountains lie between 1500 and $2100 \mathrm{~m}$ with run-out zones as low as $500 \mathrm{~m}$. Base elevations for ski areas and mountain-pass elevations range from 900 to $1800 \mathrm{~m}$.

The perennial snow line is about $2300 \mathrm{~m}$ in the Olympic Mountains and about $2500 \mathrm{~m}$ in the Cascade Mountains. The typical winter snow line is between 400 and $600 \mathrm{~m}$. However, mid-winter freezing levels vary frequently from sea-level to as high as $3000 \mathrm{~m}$. In addition, cold Arctic air that pools on the east side of the Cascade Mountains often drains through the passes. This causes persistent temperature inversions, sometimes as deep as $2000 \mathrm{~m}$, both on slopes east of the crest as well as through the passes. Occasional west-slope inversions also occur; however, these typically remain shallow and are transient. 


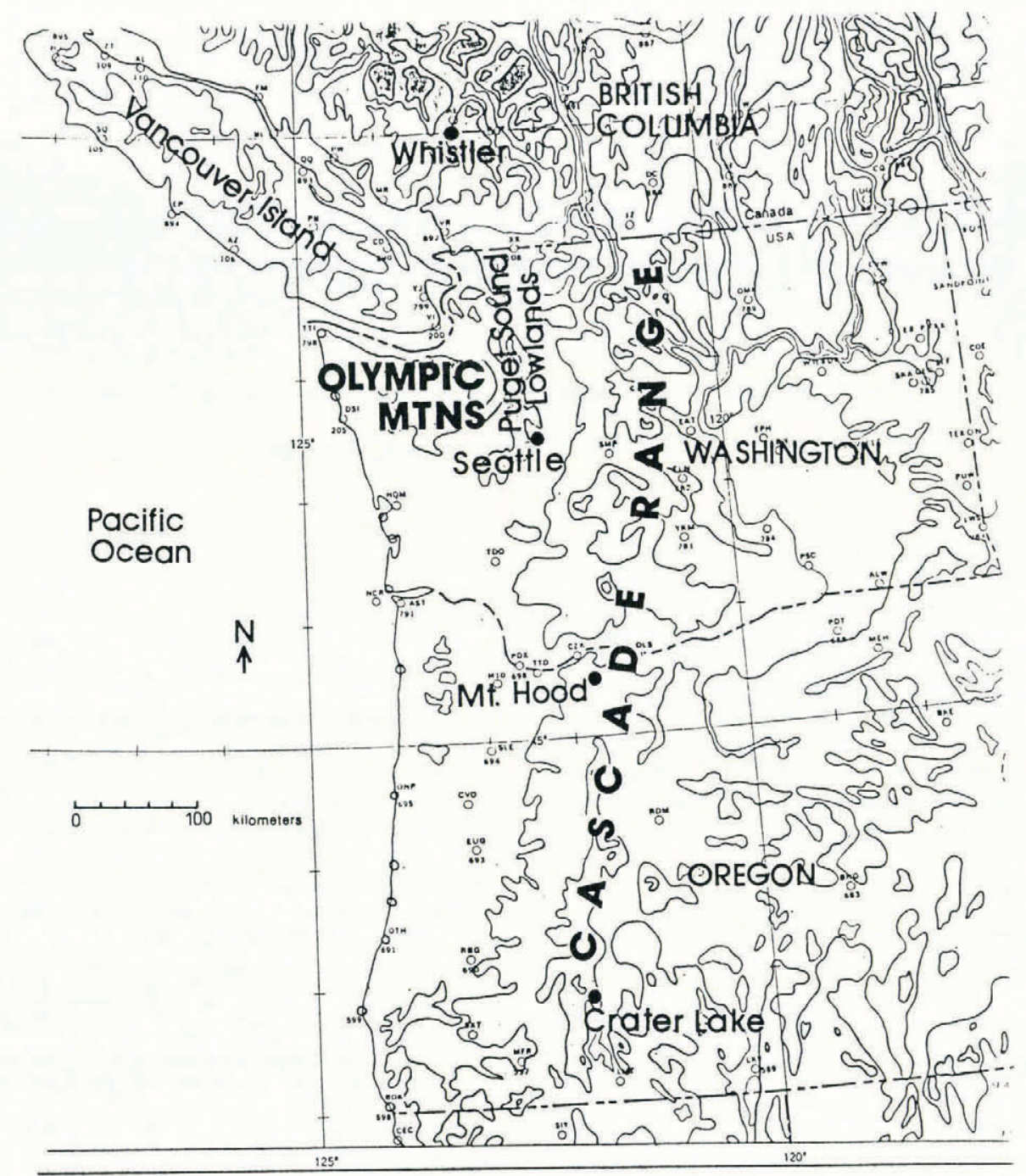

Fig. I. The Northwest Avalanche Center's forecast area. Daily forecasts are prepared for the Olympic Mountains and Cascade Mountains between Mount Hood and the Washington/Canadian border. Special forecasts are issued for Crater Lake, Oregon, and Whistler Mountain, British Columbia. (Contour intervals are approximately $700 \mathrm{~m}$.)

The wide fluctuations in winter freezing levels create a multi-layered snow-pack with many buried crusts and alternating layers of soft, low-density snow. This causes a complex interaction of strengths and weaknesses within the snow cover.

\section{Orientation}

Because the Olympic Mountains are a circular massif, winds from all directions should produce significant orographic precipitation. However, the Olympic Mountains are often protected from north and east winds by the Vancouver Island Range and the Cascade Mountains, respectively.

The north-south oriented Cascade Mountains cause maximum orographic precipitation during periods of east and west winds. Precipitation is further enhanced as these winds are funnelled through the major passes. South and north winds usually flow along the crest, producing limited orographic precipitation, and obtaining their greatest lift when they encounter the major volcanic peaks that extend above the mean Cascade crest.

The prevailing westerlies bring numerous storms into the area from the Pacific. These are usually dissipated by their passage over the west slopes of the Cascade Mountains, causing precipitation to diminish rapidly as the weakened storms move east of the Cascade crest.

\section{Site-specific climatology}

The Olympic Mountains and west side of the Cascade crest are influenced most by relatively wet, warm marine air from the Pacific Ocean where frequent storms deposit $10-30 \mathrm{~m}$ of snowfall each winter. The east side of the
Cascade crest is influenced most by relatively dry, cool Arctic air that pools in the Columbia Basin. There can be long periods between significant snowfalls. This results in a relatively shallow snow-pack that is of ten recrystallized during periods of enhanced temperature gradients.

There is no distinct boundary between the air masses on the west and east side of the Cascade Mountains. Air from one side will of ten move across the range producing dramatic weather contrasts over short distances and over short periods of time.

This shifting of dominant air masses is most frequent within the lower elevations of the passes but may extend along the entire length of the Cascade crest many times each winter. Snow-pack stratigraphy and stability in these areas often reflect these rapid shifts, which may occur within a few minutes. For example, an approaching surface low center frequently causes strong east-west pressure gradients that draw cold air across the Cascade passes. This may cause precipitation to remain as snow at the pass level while the warm sector of the storm is raising free-air freezing levels well above the pass level on the west side of the Cascade Mountains.

As soon as the low center moves to the east of the mountains, gradients shift and a warmer west wind will cause snow to change to rain. The rain-wetted new snow may avalanche within $10-30 \mathrm{~min}$ of the temperature shift.

Figure 2 shows the erosion of such a cold dome and its associated easterly pass flow in the Snoqualmie Pass region on 10 January 1988. Easterly winds maintained a temperature inversion in the pass region until 18.00 PST. Earlier that morning the avalanche-control team caused small soft slabs to release in avalanche paths just west of the 


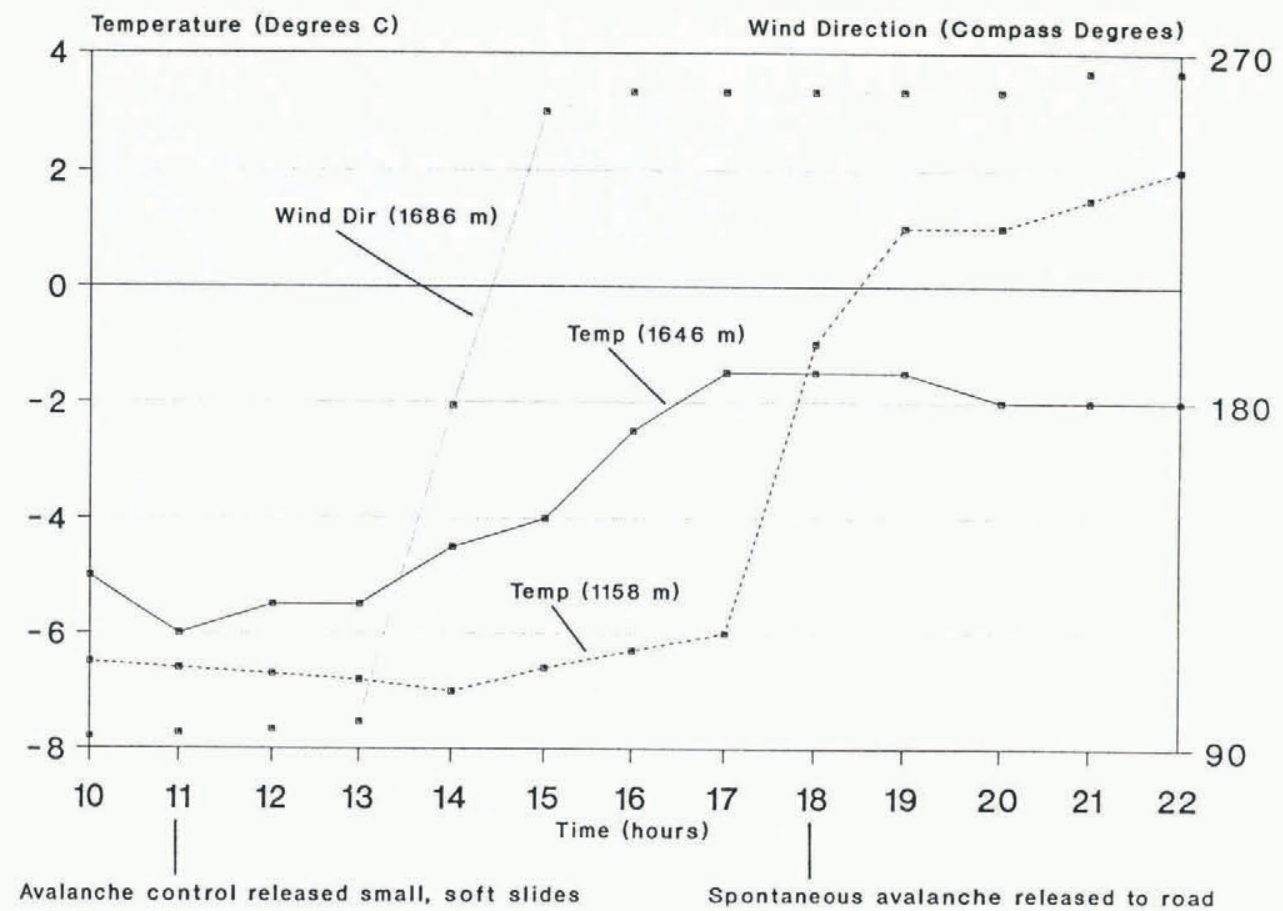

Fig. 2. Wind and temperature changes during the disintegration of a cold-air dome and associated easterly pass flow in the Snoqualmie Pass region of Washington's Cascades on 10 January 1988. DOT data (1158 m temperature) and avalanche information are from Conway and Raymond (1988).

pass. At 13.00 PST, winds began to shift above the pass at an elevation of $1686 \mathrm{~m}$. This caused a rise in temperatures to begin at the $1646 \mathrm{~m}$ elevation.

The dome of cold air further eroded to lower and lower elevations. At 17.00 PST, observers reported a wind shift at the $1158 \mathrm{~m}$ elevation and this caused an associated rise in temperatures. Almost coincidentally, avalanche activity began in the previously controlled area less than a kilometer away. At least one slide blocked the highway. The starting zone was at about $1000 \mathrm{~m}$.

NWAC's extensive array of sensors along major highway corridors over the Cascade Mountains has been used to help understand these precipitation, temperature, and snow-stability regimes associated with weather changes from cold easterly surface flow across the passes. NWAC forecasters can now predict the extent and duration of this cold air. This prediction is strategic for highwaymaintenance programs that are affected by associated freezing rain and avalanche-control teams who must prepare for widespread avalanching caused by a sudden shift from snowfall to rain. The ability to predict such changes is a crucial part of NWAC's avalanche weather program and vital to public safety in Washington and Oregon mountains.

In this and other areas where regular weather and snow-pack observations are obtained, a precise description of terrain and climatology is catalogued. These microclimatology descriptions are used to train new NWAC forecasters and help in forecasting quantitative precipitation amounts. In addition, National Weather Service (NWS) forecasters refer to the information to enhance their mountain-zone forecasts.

\section{AVAILABLE DATA}

One of the primary requirements of successful microand mesoscale forecasting programs is constant and reliable weather feed-back from the forecast area. This allows forecasters to improve the accuracy of available prognostic models by utilizing a denser array of data. Each season, NWAC adds to or changes its data network data to optimize forecast needs. For a more complete discussion of data accuracy and value to mesoscale forecasting, the reader is referred to Marriott and Moore (1984).

Over 60 mountain stations supply weather and snow-pack data to the NWAC at least once a day. Many stations report several times a day and remotely instru- mented sites are interrogated every hour. This information is combined with meteorological data provided by the U.S. National Weather Service (NWS), and the Canadian Atmospheric Environment Service (AES). Below is a summary of each data category.

\section{NWS and AES surface stations}

Approximately 75 NWS and AES stations within Washington, Oregon, and British Columbia are used by NWAC forecasters to observe hourly values and changes in atmospheric pressure, wind speed and direction, temperature, humidity, precipitation, and sky cover. Additional information is available from automated buoys and occasional trans-Pacific ships and pilot observations. Stations in California, Alaska, Idaho, and Alberta are also observed when their weather is expected to influence the Northwest.

Although most of these stations are not in the mountains, they do provide a high concentration of timely data that can be used for observing frontal passage, surface winds, etc. These observation stations are spaced $30-80 \mathrm{~km}$ apart. Figure 3 shows the location of NWS and AES surface stations regularly used by the Northwest Avalanche Center.

\section{SCS stations}

U.S. Soil Conservation Service's (SCS) meteorological information is acquired by calling their computer once a day. These data provide daily values of temperature and precipitation for at least 45 automated climate stations located within the Oregon and Washington Cascade Mountains at elevations between 980 and $1980 \mathrm{~m}$, averaging $1370 \mathrm{~m}$.

Although these observations are not frequent, they do provide a valuable areal coverage of new snow amounts and temperature fluctuations (Barton and Burke, 1977). These observation stations are spaced $20-60 \mathrm{~km}$ apart.

\section{Ski-area and highway reports}

Snow and weather reports are available from 12 ski areas, three National Parks, and nine mountain highways within Washington, Oregon, and British Columbia at least once per day. Although the amount of data from each location varies, personal contact with knowledgeable individuals at each site allows access to reliable information about atmospheric pressure, wind speed and direction, temperature, precipitation, snow depth, sky cover, current weather trends, snow-pack stability, and avalanche occur- 


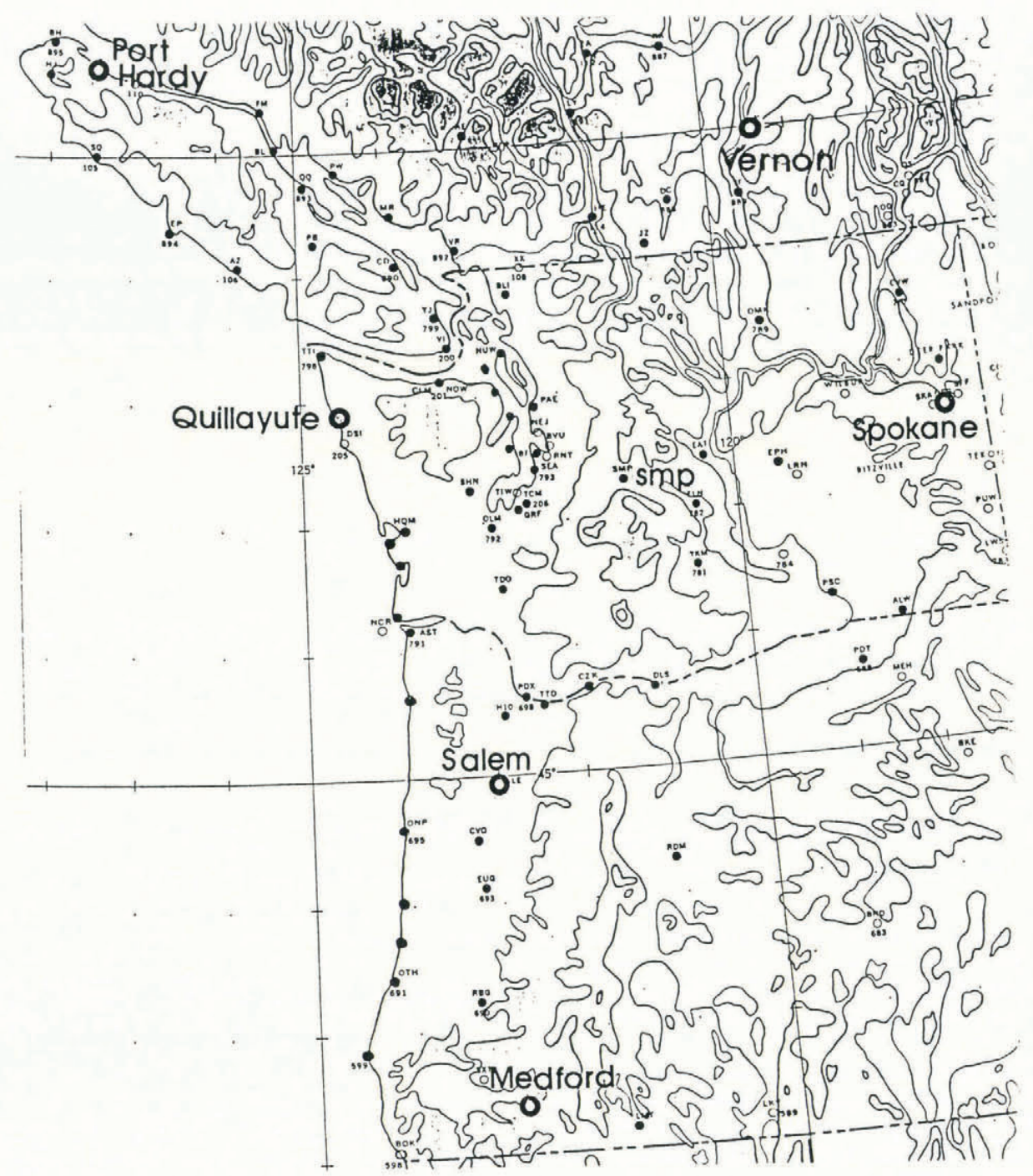

Fig. 3. U.S. National Weather Service and Canadian Atmospheric Environment Service surface-observation stations used by the Northwest Avalanche Center. Open circles show sites where radiosonde data are obtained in addition to surface observations. smp, Stampede Pass.

rence. These observation stations are spaced $10-80 \mathrm{~km}$ apart as shown in Figure 4.

\section{Radiosonde data}

NWS and AES weather balloons are released twice a day to retrieve information about the upper atmosphere. Six stations are regularly used by NWAC: Port Hardy (a BC coast station), Vernon (a BC interior station), Quillayute (a Washington coast station), Spokane (a Washington interior station), and Salem and Medford (Oregon stations just west of the Cascade crest). These observation stations are spaced $200-300 \mathrm{~km}$ apart as shown in Figure 3.

\section{NWAC automated stations}

Ten to 12 stations are installed and maintained by NWAC each winter. Remote micro-loggers record hourly information from weather sensors, which is then transmitted to the NWAC. Three stations transmit via GOES satellite to the USDA-FS fire weather computer in Boise Idaho (BIFC), then to the FS AFFIRMS computer in Fort Collins, Colorado. The AFFIRMS computer is interrogated by the NWAC computer. (Much of the equipment for these stations is shared seasonally with the Forest Service fire weather program.) One station is interrogated through a VHF radio that is connected to a telephone modem. Six stations have telephone modems directly connected to the remote microloggers for immediate interrogation.

At the NWAC office, an IBM-AT compatible, multitasking computer automatically calls each site every $3 \mathrm{~h}$, $24 \mathrm{~h}$ a day. The raw data are then manipulated into readable columns. Data are available to NWAC co-operators throughout the region through a computerized bulletin board on the same computer. Also, the data are transferred automatically to the NWS AFOS computer for use by their forecasters. Stations (except GOES sites) can be called at any other time by NWAC forecasters for updated observations as needed.

Whenever possible, these remote stations are constructed to record temperature at three different elevations, with wind speed and direction at the highest, ridge-top elevation, and humidity and precipitation at the mid or base. In addition to providing inputs and verification for weather forecasts, these data are used by NWAC forecasters to reconstruct empirically the snow layering when more direct snow-cover observations are absent or incomplete.

To support these activities, forecasters have helped develop new sensor technology appropriate to a harsh mountain environment. For example, forecasters have collaborated with a local engineer ( $P$. Taylor of Seattle, Washington) to develop and test internally heated anemometers and wind vanes to operate reliably even during the most severe maritime rime-icing storms. These rugged sensors are now available commercially, having been installed at mountain sites for operational weather and avalanche-forecasting programs from Finland to New Zealand.

NWAC automated observation stations are spaced $30-50 \mathrm{~km}$ apart as shown in Figure 4.

\section{Satellite imagery}

Full disc (7 km resolution) and sector $(4,2$, and $1 \mathrm{~km}$ resolution) images of visible $(0.55-0.75 \mu \mathrm{m})$, infrared 


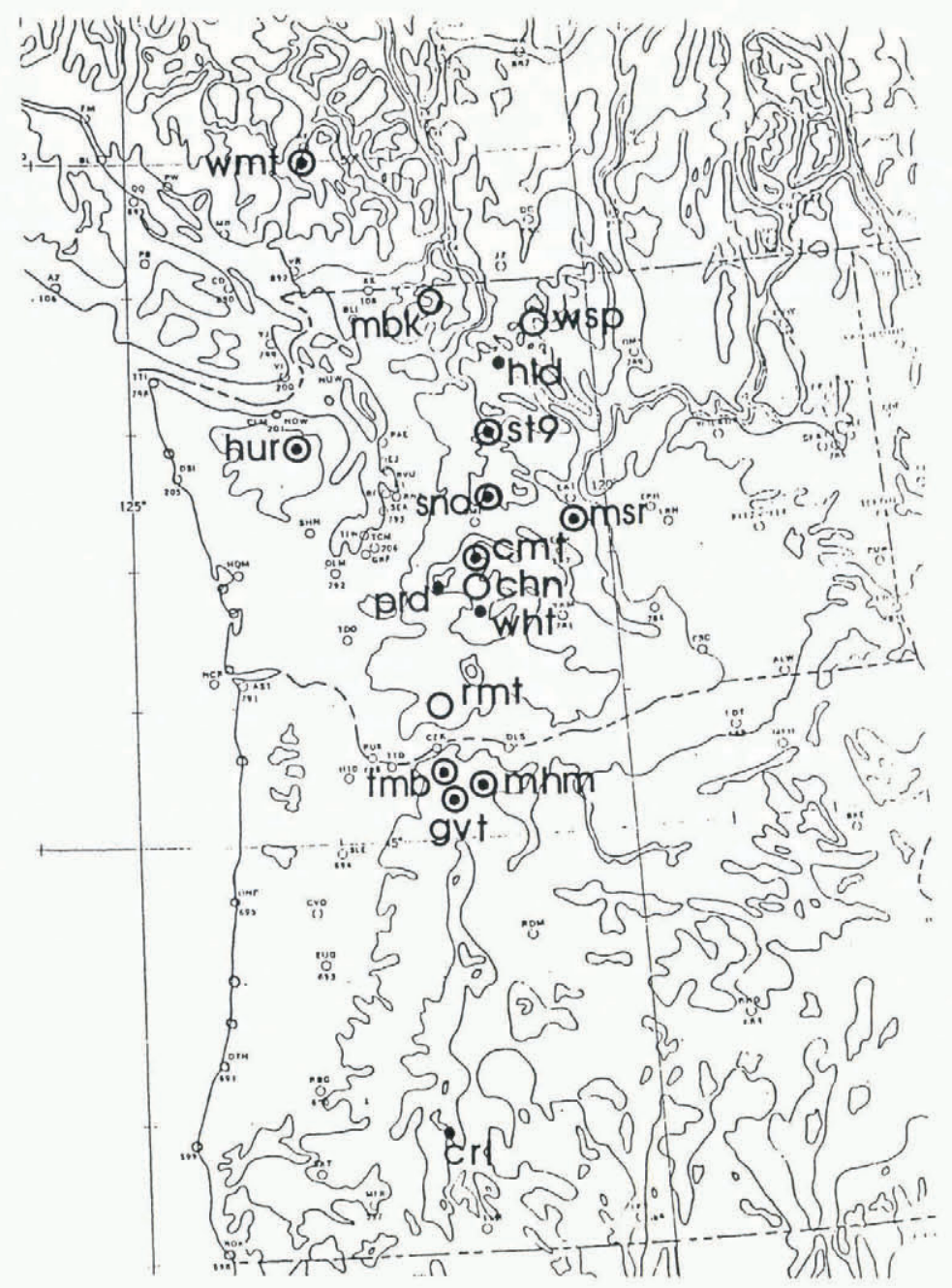

Fig. 4. Ski area, highway, and automated observation stations used by the Northwest Avalanche Center. Open circles show locations of automated stations. Closed circles show locations of manual observations. Open circles surrounding closed circles have both. wmt, Whistler Mountain; mbk, Mount Baker; wsp. Washington Pass; hld, Holden Village; st9. Stevens Pass; hur, Hurricane Ridge; sno. Snoqualmie Pass; msr. Mission Ridge; cmt, Crystal Mountain; chn, Chinook Pass; prd, Paradise (Mount Rainier); wht, White Pass; rmt, Red Mountain; tmb. Timberline; mhm, Mount Hood Meadows; gvt. Government Camp; crl, Crater Lake.

$(10.0-12.5 \mu \mathrm{m})$, and water vapor $(6.7$ and $7.3 \mu \mathrm{m})$ are available from the GOES West Satellite through the NWS SWIS (Satellite Weather Information System) scheduler once or twice each hour. These can be color-enhanced, timelooped, and overlain with graphic plots of observed data. Satellite photographs provide ways to (1) observe cloud cover between observation stations, and (2) recognize and follow the development of mesoscale storms or shower bands that fall between the grid spacing of availab!e synoptic forecast models.

\section{Radar}

Four Federal Aviation Administration radars $(23 \mathrm{~cm}$ wavelength) and one NWS (10 cm wavelength) radar in Washington and Oregon, operating on each side of the Cascade Mountains, transmit data to the Seattle NWS forecast office. These data are available every few minutes and help locate areas of heavy precipitation that may be approaching the mountains.

\section{NORTHWEST AVALANCHE CENTER OPERATION}

The Northwest Avalanche Center uses the abovedescribed data to forecast mountain weather and its influence on avalanching. Although synoptic prognostic models use AES and NWS data for initialization, much of the model interpretation and data analysis is left to the individual forecaster. To help understand the process of data analysis and avalanche weather forecasting, a brief description of the Center and its organization follows.
The NWAC began in 1975 as a research project at the University of Washington, funded by the Washington Department of Transportation and Federal Highway Administration (LaChapelle and others, 1976, 1977, 1978). Now, it is administered by the USDA-Forest Service and is a co-operatively funded program with the Washington State Department of Transportation, the National Weather Service, National Park Service, Northwest ski areas, and several other private groups and agencies. The forecast office is central and co-located with the NWS forecast office in Seattle.

The task of the Center is two-fold: (1) to prepare micro- and mesoscale mountain weather forecasts for use by avalanche- and snow-safety programs, and (2) to prepare detailed snow-pack analyses and hazard forecasts for public dissemination. This paper describes the weather-forecasting part of the program only. While some modification of the avalanche forecasts produced by the Center have occurred in the last few years, the basic framework has been described in Marriott and Moore (1981).

The Center employs four forecasters who are trained in meteorology, snow physics, and avalanche mechanics. This allows forecasters to combine traditional weather analysis and forecasting tools with a knowledge of terrain effects on local weather and subsequent effects on avalanche conditions.

The forecasters share office duties, with rotating shifts as Duty Forecaster of $3 \mathrm{~d}$ at a time. Only one forecaster is on duty in the office each shift. The rest of their work week is spent in pairs in the mountains. Field work includes analyzing snow stability and snow layering as 
related to past and current weather, familiarization with local climates and avalanche terrain in various parts of the forecast region, participating in avalanche-control activities, communicating with forecast users and other field observers, installing and repairing instrumentation, and helping teach in avalanche and mountain-weather training programs.

Preparation for the forecast season begins in September and includes equipment installation, updating computer programs, and research and development. Daily forecasts usually begin about mid-November or whenever enough snow accumulates at low elevations.

A typical day in the forecast office starts at 03.30 PST. The Duty Forecaster begins by reviewing the previous night's weather as reported by the automated weather telemetry stations. These data are compared with NWS initial analysis maps to verify accuracy. A review and analysis of current NWS prognostic charts is then begun.

The first field observer telephones the center at 04.00 PST. At this time, the forecaster has a cursory idea of the expected weather for the next $12 \mathrm{~h}$ and can begin briefing this and subsequent field personnel as they telephone their observations. After reviewing all data and computerized prognostic charts, the mountain-weather forecast is composed and available by 07.00 PST.

During critical situations, the forecaster is available throughout the day to monitor weather and inform field personnel of current conditions. A formal update on the weather forecast is prepared and disseminated by 15.00 PST. The forecaster will leave the office between 15.30 and 16.30 PST, remaining on call throughout the night.

Daily forcasting usually terminates around mid-April. However, weather forecasts are issued to highway departments until all seasonal mountain passes are opened and cleared. This may require forecasts well into June but typically all roads are open by mid to late May. In addition, special public avalanche statements are issued whenever the snow and weather situation deviates significantly from expected springtime conditions.

Two forecasters remain on duty through June to catalog, analyze, and archive data and to remove instrumentation. In addition, the status of the field data network and office operations are assessed to plan for the next season's necessary changes.

\section{ANALYSIS AND FORECASTING TECHNIQUES}

An example of NWAC forecast output is shown in Appendix A. The basic parts of the forecast include: (1) a weather synopsis of current and expected conditions; (2) a weather forecast for days 1-2, separated into expected climate regimes; (3) the expected freezing/snow levels for 6 $-12 \mathrm{~h}$ periods for days $1-2$, separated into climate regimes; (4) $24 \mathrm{~h}$ forecasts of water-equivalent precipitation for days $1-2 ;(5)$ wind forecasts at the pass level; (6) wind forecasts for free-air flow at 1500 and $2700 \mathrm{~m}$; and (7) an extended forecast for $3-5 \mathrm{~d}$.

Because the forecast region is so large, the influence of each storm varies dramatically over the area. Therefore, specific climatic regimes are identified whenever possible. For example, storms passing to the north may influence only the northern forecast region, storms recirculating around a low centered in Oregon or California may influence only the east slopes of the Cascade Mountains, and storms stalled over the coast may influence only the Olympic Mountains. When there are strong temperature inversions, elevation distinctions are also made for each weather forecast. The following describes how forecast products are determined.

\section{Cloud cover}

Satellite images are used to estimate current cloud type and top temperature. Manned observation stations give per cent of current cloud cover and cloud-ceiling elevation. Radiosonde data are used to determine current lifting condensation level. These data along with lifting mechanisms determined from prognostic charts and trajectories of up-stream cloud formations are used to forecast expected cloud cover. Cloud cover plays a vital role in many aspects of avalanche formation and control. For example, clouds significantly influence the heat balance and subsequent

stability of snow. Clouds also hamper helicopter flying that is done for guided ski tours, avalanche control, rescue missions, and special projects. Therefore, particular effort is made to forecast the timing and extent of cloud cover as closely as possible.

Standard cloud-cover categories of clear, partly cloudy, broken, overcast, and fog are used in the forecast summary. An estimate of timing is also included, like "slow midmorning clearing," or "increasing clouds in the early afternoon". In addition, distinctions of lower, mid, and upper, are used whenever describing strato-, alto-, or cirrotype clouds, respectively. If a temperature inversion exists that causes cloudiness, specific elevation is given.

\section{Freezing/snow level}

Mean free-air freezing levels within avalanche terrain are interpolated from radiosonde data. The temperature observations from all mountain stations, and snow-level observations from field personnel are used to fine-tune freezing-level estimates and allow for inversions within the mountains.

NWS prognostic charts compute $1000-500 \mathrm{hPa}$ atmospheric thicknesses for each $12 \mathrm{~h}$ period for days 1-2 and in $24 \mathrm{~h}$ periods for days $3-5$. This information is combined with current observations to forecast freezing levels within $150 \mathrm{~m}$ and timing of change during days $1-2$. For days $3-5$, the freezing-level forecast is within a $600 \mathrm{~m}$ range and a more general indication of changes is given.

When precipitation is expected, snow level rather than freezing level is given. This is usually about $300 \mathrm{~m}$ below the expected freezing level.

\section{Free-air winds}

Instantaneous wind speed and direction for several levels of the atmosphere are obtained from radiosonde observations. These data are combined with observations from NWAC's automated ridge-top anemometers to estimate current winds.

NWS prognostic charts give $12 \mathrm{~h}$ forecasts of 850 and $700 \mathrm{hPa}$ heights. These are used with forecasts of other weather influences (e.g. gusts in the vicinity of showers) to evaluate free-air wind speed and direction at 1500 and $2700 \mathrm{~m}$ in $12 \mathrm{~h}$ periods for days $1-2$.

\section{Pass winds}

Wind flow through the Cascade passes usually does not follow the free-air pattern. Measurements of pass winds are obtained from three primary anemometers, at Stevens, Snoqualmie, and Stampede Passes. The winds are forecast using a combination of expected upper-level wind and surface-pressure gradient forecasts from NWS prognostic charts.

Table I shows a guideline that NWAC created and now uses for estimating pass winds. It is based on empirical studies of hourly and mountain-station observational data.

\section{Precipitation rate}

NWAC precipitation rates are given as light, moderate, or heavy for each $6 \mathrm{~h}$ period during the $2 \mathrm{~d}$ forecast. This

\section{TABLE I. GUIDELINE FOR ESTIMATING PASS WINDS}

Pressure gradient

$S E A-Y K M$

in $\mathrm{hPa}$

$$
>+2
$$$$
+1,0
$$$$
-1,-2,-3
$$

SEA, Seattle in western Washington.

YKM, Yakima in eastern Washington. 
scale loosely follows NWS guidelines for precipitation rate in valley locations but has been adjusted to account for effect on snow-pack stability and to account for more typical mountain-precipitation values. Table II shows precipitationrate categories developed and used by the NWAC.

Current precipitation rate is obtained from field observations at 12 locations and from ten instrument sites (heated, tipping-bucket precipitation gages). Forecasts of precipitation rate are developed by determining (a) the type and strength of lifting mechanisms, and (b) the duration of

TABLE II. GUIDELINE FOR MOUNTAIN PRECIPITATION RATE

$\begin{array}{lc}\text { Rate } & \mathrm{mm} / \mathrm{h} \\ \text { Light } & <0.75 \\ \text { Moderate } & 0.76-1.25 \\ \text { Heavy } & 1.26-1.75\end{array}$

lifting. Appendix B briefly explains weather situations that have been observed to cause light, moderate, or heavy precipitation rates in the Cascade Mountains.

\section{Precipitation amount}

Because precipitation in the Northwest can fall as rain or snow, all precipitation forecasts are given in water equivalents (WE). Appendix B summarizes guidelines developed and used by NWAC forecasters that help them generate $24 \mathrm{~h}$ quantitative precipitation forecasts (QPF). The guidelines are based upon 13 years of observation. The resulting forecasts give the lowest expected value and the highest expected value with a range of $6 \mathrm{~mm}$ for amounts less than $25 \mathrm{~mm}$ and a range of $22 \mathrm{~mm}$ for amounts greater than $25 \mathrm{~mm}$.

There is wide spatial variability of precipitation amounts in the Cascade and Olympic Mountains. This is primarily due to the variable lifting caused by complex terrain and is dependent upon surface and free-air wind-flow patterns and atmospheric stability. To illustrate this variability, $24 \mathrm{~h}$ precipitation accumulations at four sites during a $10 \mathrm{~d}$ period in January 1983 are displayed in Figure 5. Mission Ridge is on the east side of the central Washington Cascades; Stevens Pass is about $64 \mathrm{~km}$ west- north-west near the Cascade crest. Hurricane Ridge is on the north-east corner of the Olympic Mountains and Mount Rainier is a volcanic peak in the south, central Washington Cascades.

This $10 \mathrm{~d}$ period represents a typical storm cycle. The smallest difference of precipitation between stations is $32 \mathrm{~mm}$ (data are missing from Mission Ridge on days 5,9 , and 10). This observed range is well beyond the typical range of QPF values given for each forecast period. For this reason, separate QPFs are given for selected high-usage areas as shown in Appendix A.

\section{PRECIPITATION MECHANISMS}

At this time, microscale, quantitative precipitation guidance is not available for operational mountain forecasts in the Northwest. However, NWS forecast models generate 6 and $12 \mathrm{~h}$ precipitation maps and vertical velocities from expected synoptic-scale cyclonic and frontal lifting. These model outputs are only useful as general range indicators (i.e. light, moderate, and heavy precipitation). Therefore, micro- and mesoscale precipitation forecasting at the NWAC is largely based upon empirical guidelines developed during the previous 13 years of operation and the subjective experience and skills of each individual forecaster. Precipitation guidelines developed and used by NWAC forecasters are outlined below.

Persistent and frequent temperature inversions significantly complicate the precipitation forecast as precipitation type (e.g. snow, rain, or freezing rain) may vary dramatically, both temporally and spatially. Since this variation can produce extreme consequences in snow stability, timing of such a change is critical. To maximize advance warning time, forecasters rely heavily on hourly data from multiple elevation temperature and wind sensors near several Cascade passes, as well as extrapolation of cloud motion depicted in satellite imagery.

These data must be combined with an estimate of lifting mechanisms in order to develop a complete precipitation forecast that includes precipitation type, rate, amount, and timing of changes. There are five main types of lifting that affect the Northwest mountains: (1) frontal, (2) orographic, (3) cyclonic, (4) convergent, and (5) convective. Each mechanism plays a significant role in the production of precipitation, with their specific influence dependent upon the existing weather pattern.

For example, the heaviest precipitation amounts in the

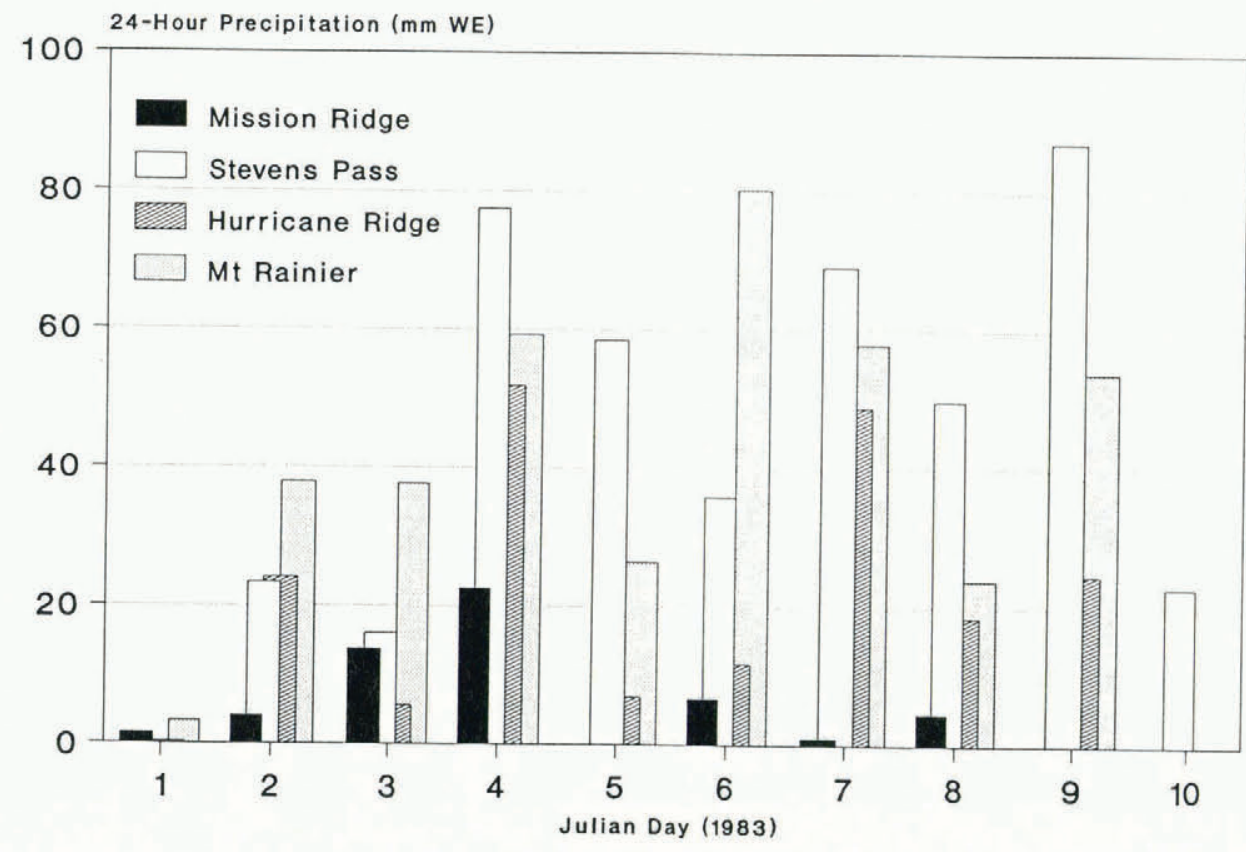

MIsolon Ridge data Is missino
for days 5,9 , and 10 .

Fig. 5. Comparison of $24 \mathrm{~h}$ precipitation at selected sites in the Washington Cascade and Olympic Mountains during 1-10 January 1983. 
Olympic and Cascade Mountains are usually produced by a series of fronts embedded in a strong south-westerly flow which is tapping sub-tropical moisture. These fronts are usually broad and become nearly stationary over Washington/Oregon or along the coast, with frontal movement identifiable only by the onset of heavy precipitation. Heavy over-running precipitation ahead of these fronts is enhanced by cold air pooled in either western Washington/Oregon (additional up-slope effect) or eastern Washington/Oregon (wedge of cold easterly air flow over the Cascade passes). Waves of ten develop on the back edge of approaching fronts which may slow its progression and produce areas of enhanced precipitation. Cold polar air following major fronts of ten organizes into secondary frontal systems over the ocean, producing a series of fronts. As these fronts progress eastward over the area, it becomes difficult to distinguish one from another. Frontal lifting produces very small amounts of precipitation when frontal passage is rapid or when a north-south aligned front is accompanied by southerly winds.

In many significant storm systems, $60-70 \%$ of the precipitation is post-frontal orographic. The extent of potential orographic precipitation is judged by the strength of the westerly component of wind at 850 and $700 \mathrm{hPa}$ levels, the amount and trend of moisture in radiosonde soundings, and amount of moisture as forecast by NWS computer prognoses of relative humidity. An unstable air mass will enhance lifting and this is determined with satellite imagery and radiosonde data.

A two-dimensional orographic precipitation model based upon a wind-flow model for the Cascade and Olympic Mountains has been developed by Speers (unpublished). This model has been tested and should prove to be a valuable guide for quantitative precipitation forecasts (QPFs). It is now being adapted for use on an IBM-compatible 386, so it can be used operationally.

Precipitation from cyclonic lifting is determined from NWS prognostic charts that forecast relative vorticity, which is circulation per unit area of air. Experience has shown that positive vorticity greater than 10 that is accompanied by relative humidity (in the $1000-500 \mathrm{hPa}$ air column) greater than $70 \%$ will produce light to moderate precipitation in the mountains.

The circular Olympic Mountains of ten split incoming north-westerly winds. These winds reconverge in the Puget Sound Lowlands and can cause enhanced precipitation with the accompanying convergent lifting. This zone of enhanced cloudiness and precipitation is called the Puget Sound Convergence Zone and is usually about $100-200 \mathrm{~km}^{2}$. As it pushes against the Cascade Mountains, precipitation is further enhanced over a relatively small area.

Local convergence zones are also caused by flow around volcanic peaks and channelled flow through several river drainages. The volcanic peaks can affect flow from any direction, while the predominant river drainages tend to channel west and south-west winds in the Olympic Mountains and west, south-west, east, and south-east winds in the Cascade Mountains. Local convergence zones are on the order of $10-100 \mathrm{~km}^{2}$.

Snowfall differences of $20 \mathrm{~cm}$ or more are common over the space of a few kilometers when a convergence episode occurs. However, the timing, location, and extent of convergence zones are difficult to predict. Although the Puget Sound Convergence Zone is often large enough to be recognized on the mesoscale network of observation stations around the Sound, other, smaller convergence zones fall well between observation stations. In addition, no synoptic model is yet capable of predicting the onset of these mesoscale events.

Convective precipitation is the most difficult type of precipitation to forecast because the scale of convective activity is small compared to other mechanisms. Although convection plays its most significant role in the spring and summer, with each cold frontal passage during the winter a period of instability can cause convective showers that enhance orographic lifting.

\section{DISSEMINATION}

The complete mountain weather forecast and each update is transferred to NWAC's IBM-AT-compatible computer bulletin board. This is available for computer callers $24 \mathrm{~h}$ a day throughout the season. In addition, the weather forecast is appended to the avalanche forecast and sent to the Forest Service's AFFIRMS computer and the Forest Service's DG computer system. The forecast is also recorded on a code-a-phone for $24 \mathrm{~h}$ telephone access. During critical situations, the forecaster is available throughout the day to monitor weather and inform field personnel of current and expected conditions.

\section{CONCLUSION}

As with any weather forecast, the accuracy of NWAC's avalanche weather forecasts depend upon the type of storm, the accuracy of the theoretical modeling or available guidance, and the forecaster's experience. In addition, with very little observation data within the up-wind Pacific Ocean, many storms are not completely analyzed until they reach the coast. At that time, a storm's characteristics may change rapidly as it loses its over-water trajectory and moves over complex terrain. Rapid and subtle changes often occur below the resolution of prognostic model grids. These can cause large enough variations in the weather pattern to upset the accuracy of the subsequent model outputs, causing an increased burden on the avalanche weather forecaster's own analytic abilities.

Despite these difficulties, forecasters at NWAC strive to provide a useful program for avalanche-control workers and highway-maintenance personnel throughout the Cascade and Olympic Mountains. Instrument designs, forecast models, and functions within NWAC's entire program are continually modified and updated as new ideas and needs are expressed. Several heretofore unknown aspects of mountain weather have been discovered through NWAC's analysis of the large volume of data that is accumulated during each operational season. In addition, site- and time-specific weather parameters have been quantified and identified as avalanche-producing events.

NWAC's unique program has proven beneficial to highway-maintenance and snow-safety programs throughout Washington and Oregon. It is hoped that the observation and analytic techniques described in this paper will additionally benefit forecast programs in other alpine areas.

\section{REFERENCES}

Barton, M. and M. Burke. 1977. SNOTEL: an operational data acquisition system using meteor burst technology. Proceedings of the Western Snow Conference, 45th annual meeting, 82-87.

Conway, H. and C.F. Raymond. 1988. Predictions of snow avalanches in maritime climates. Olympia, WA, Washington State Department of Transportation. (Report on Research Project GC8286, Task 8.)

Fox, T.D. Unpublished. Avalanches and synoptic weather situations in the Washington Cascades in the 1971-72 winter. (Master's thesis, University of Washington, Seattle, 1973.)

La Chapelle, E.R., R.T. Marriott, M.B. Moore, F.W. Reanier, E.M. Sackett, and P.L. Taylor. 1976. Central avalanche hazard forecasting; interim report. Phase II. Olympia, WA, Washington State Highway Department. (Research Program Report 23.2.)

La Chapelle, E.R., R.T. Marriott, M.B. Moore, F.W. Reanier, E.M. Sackett, and P.L. Taylor. 1977. Central avalanche hazard forecasting. Final report. Phase II Olympia, WA, Washington State Highway Department. (Research Program Report 23.3.)

LaChapelle, E.R., and 6 others. 1978. Central avalanche hazard forecasting; a summary of scientific investigations. Olympia, WA, Washington State Highway Department (Research Program Report 23.4.)

Marriott, R.T. and M.B. Moore. 1981. Northwest avalanche forecasting program - form, content, dissemination, usage. In Canadian Avalanche Committee, ed. Proceedings of Avalanche Workshop, 3-5 November 1980, Vancouver. Ottawa, National Research Council of Canada. Associate Committee on Geotechnical Research, 190-204. (Technical Memorandum 133.) 
Marriott, R.T. and M.B. Moore. 1984. Weather and snow observations for avalanche forecasting: an evaluation of errors in measurement and interpretation. In Proceedings of International Snow Science Workshop, Aspen, Colorado, Oct. 24-27, 1984, 143-154.

Moore, M.B. Unpublished. Weather and snowpack developments associated with avalanching in the Washington Cascades. (Master's thesis, University of Washington, Seattle, 1975.)

Speers, P. Unpublished. Diagnosis and prediction of precipitation in regions of complex terrain. (Master's thesis, University of Washington, Seattle, 1986.)

\section{APPENDIX A}

SAMPLE OF NWAC'S MOUNTAIN WEATHER FORECAST PRODUCT*

NW AVALANCHE CENTER ... FOR OFFICIAL USE ONLY MOUNTAIN WEATHER AND AVALANCHE FORECAST FOR

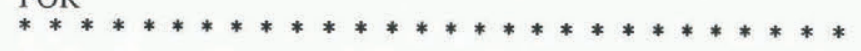

7 AM WEDNESDAY JANUARY 131988

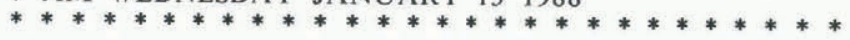

\section{WEATHER SYNOPSIS}

A WEAKENING WEATHER SYSTEM MOVED THRU THE PAC NW TUESDAY NIGHT... BRINGING SNOW TO MOST AREAS OVERNIGHT. THE ASSOCIATED COLD FRONT CROSSED THE CASCADES EARLY WED MORNING FOLLOWED BY MORE SHOWERY PRECIPITATION. WEAK HIGH PRESSURE EXPECTED TO BUILD OVER THE REGION WED MORN SHOULD RESULT IN DECREASING SNOW SHOWERS... HOWEVER ... AS THE RIDGE SLOWLY MOVES EAST OF THE REGION WED AFT... WARM OVERRUNNING CLOUDS AND LIGHT PRECIPITATION FROM THE NEXT APPROACHING WEATHER SYSTEM SHOULD SPREAD INLAND. THIS SYSTEM IS EXPECTED TO SWING NE INTO BC AND WEAKEN WED NIGHT AHEAD OF AN APPROACHING VIGOROUS WEATHER SYSTEM... HOWEVER... IT SHOULD PRODUCE RAIN OR SNOW AND RELATIVELY STRONG WINDS IN MOST AREAS OVERNIGHT. AS THE NEXT STRONGER WEATHER SYSTEM MOVES INTO THE AREA THURS... STRONG WINDS... RISING FREEZING LEVELS AND SUBSTANTIAL OVERRUNNING RAIN OR SNOW IS EXPECTED DURING THE DAY THURS. THE ASSOCIATED COLD FRONT SHOULD MOVE THRU THE REGION LATE THURS... FOLLOWED BY SIGNIFICANTLY LOWERING SNOW LEVELS AND SNOW SHOWERS THURS NIGHT.

IN THE LONGER RANGE... WEAK HIGH PRESSURE EXPECTED TO BUILD OVER THE REGION FRI MORN SHOULD RESULT IN DECREASING SNOW SHOWERS. THIS HIGH PRESSURE IS EXPECTED TO SLOWLY MOVE EAST OF THE REGION FRI AFT AS A WEATHER DISTURBANCE APPROACHES THE COAST. . HOWEVER,.. THIS SYSTEM IS EXPECTED TO DIG SOUTHEAST INTO CAL. OVER THE WEEKEND... THE MAIN STORM TRACK IS EXPECTED TO MOVE THRU CAL... WITH THE PACIFIC NORTHWEST ON THE COOL NORTHERN SIDE OF WEATHER SYSTEMS. THIS SHOULD PRODUCE COOL SHOWERY CONDITIONS SAT AND SUN,

\section{WEATHER FORECAST WED AND THURS}

OLYMPICS - SNOW SHOWERS WED MORN... OTHERWISE... INCREASING CLOUDS WED WITH INCREASING LIGHT RAIN OR SNOW WED AFT AND NIGHT. PERIODS OF RAIN OR SNOW THURS MORN... BECOMING MOD TO OCCASIONALLY HEAVY AT TIMES THURS AFT. RAIN OR SNOW TURNING TO SNOW SHOWERS THURS NIGHT.

* Please note that NWAC forecasts are typically written in English units but have been converted to SI units for the purposes of this example.
WEST SLOPES WA CASCADES AND MT HOOD $A R E A$ - SNOW SHOWERS WED MORN. . OTHERWISE. . INCREASING CLOUDS WED WITH INCREASING CHANCE LIGHT RAIN OR SNOW LATE WED AFT AND WED NIGHT. . MAINLY IN THE NORTH. PERIODS OF RAIN OR SNOW THURS MORN... BECOMING MOD TO OCCASIONALLY HEAVY AT TIMES THURS AFT. RAIN OR SNOW TURNING TO SNOW SHOWERS THURS NIGHT.

CASCADE PASSES - SNOW SHOWERS WED MORN... OTHERWISE... INCREASING CLOUDS WED WITH INCREASING CHANCE LIGHT SNOW LATE WED AFT AND WED NIGHT. PERIODS OF RAIN OR SNOW... WITH A CHANCE OF FREEZING RAIN.. THURS MORN. RAIN OR SNOW BECOMING MOD TO OCCASIONALLY HEAVY AT TIMES THURS AFT.. AND TURNING TO SNOW SHOWERS THURS NIGHT.

EAST SLOPES WA CASCADES - VARIABLE CLOUDINESS WED MORN WITH OCCASIONAL LIGHT SNOW SHOWERS. INCREASING CLOUDS WED AFT WITH INCREASING CHANCE LIGHT SNOW WED NIGHT. . MAINLY IN THE NORTH. PERIODS OF LIGHT SNOW... WITH POSSIBLE FREEZING RAIN AT LOWER ELEVATIONS... THURS MORN... BECOMING MOD THURS AFT... AND TURNING TO SNOW SHOWERS THURS NIGHT.

CASCADE SNOW LEVEL NORTH SOUTH

\begin{tabular}{lrrl} 
IN METERS & 750 & 1050 & WED MORN \\
& 900 & 1200 & WED AFT \\
& 1200 & 1500 & AND NIGHT \\
& 750 & 1050 & THURS \\
& & \multicolumn{2}{c}{ NHGHT } \\
OLYMPIC SNOW LEVEL & 900 & WED MORN \\
IN METERS & 1100 & WED AFT AND \\
& NIGHT \\
& 1350 & THURS \\
& 900 & THURS NIGHT
\end{tabular}

\section{HOUR FORECAST OF PRECIPITATION IN MM} WATER EQUIVALENTS

ENDING AT 4AM

$\begin{array}{lcc} & \text { THURS } & \text { FRI } \\ \text { MT BAKER } & 19 & 19-25 \\ \text { STEVENS PASS } & 13 & 13-19 \\ \text { SNOQUALMIE PASS } & 13-19 & 19-25 \\ \text { WHITE PASS } & 6-13 & 13 \\ \text { CRYSTAL MTN } & 13 & 13-19 \\ \text { PARADISE } & 19 & 25 \\ \text { MT HOOD } & 13-19 & 19-25 \\ \text { HURRICANE RIDGE } & 13 & 19 \\ \text { MISSION RIDGE } & 6 & 6-13 \\ \text { WASHINGTON PASS } & 13 & 13\end{array}$

THE FOLLOWING WINDS ARE IN METERS PER SECOND

$\begin{aligned} \text { CASCADE PASS LEVEL WINDS } & \text { E 2-5 WED MORN } \\ & \text { E 3-6 WED AFT } \\ & \text { E 5-8 WITH HIER } \\ & \text { GUSTS WED } \\ & \text { NIGHT AND } \\ & \text { THURS } \\ & \text { E 3-6 THURS NIGHT }\end{aligned}$

FREE WINDS AT 1500 M

SW 6-9 WED

SW 9-13 WED NIGHT AND THURS

FREE WINDS AT $2700 \mathbf{M}$ SW 8-11 WED

SW 12-16 WED NIGHT AND THURS 


\section{EXTENDED WEATHER FORECAST FRI THRU SUN}

DECREASING SNOW SHOWERS FRI. COOL WITH SCATTERED SNOW SHOWERS SAT AND SUN. SNOW LEVELS NEAR 300-1000 M NORTH, 600-1200 M SOUTH FRI LOWERING TO NEAR SFC-600 M NORTH AND SOUTH SAT AND SUN.

\section{APPENDIX B}

SUMMARY OF GUIDELINES DEVELOPED AND USED BY NWAC FORECASTERS TO HELP THEM DETERMINE PRECIPITATION RATE AND GENERATE $24 \mathrm{~h}$ PRECIPITATION AMOUNTS

\section{HOURLY PRECIPITATION RATE}

Light

(a) No frontal activity or disspitating weak frontal activity with a stable air mass and winds less than $7 \mathrm{~m} \mathrm{~s}^{-1}$ at the pass level.

(b) A weak upper disturbance passing mostly to the north or south of the State.

\section{Moderate}

(a) Frontal activity with associated winds nearly perpendicular to front alignment.

(b) 850 mbar level winds with a westerly component of $7-12 \mathrm{~m} \mathrm{~s}^{-1}$ and $\mathrm{RH}>70 \%$, within a neutrally stable air mass.

(c) Puget Sound convergence zone created by $850 \mathrm{mbar}$ level wind from the north-west at $7-12 \mathrm{~m} \mathrm{~s}^{-1}$. area.

(d) A weak upper-level trof passing directly over the

(e) A strong upper-level trof passing mostly to the north or south of the State.
Heavy

(a) A W-SW flow $>12 \mathrm{~m} \mathrm{~s}^{-1}$ at low levels that is tapping sub-tropical moisture with cold air pooled in either western Washington (additional up-slope effect) or eastern Washington (wedge of cold easterly air flow over the Cascade passes).

(b) An unstable air mass, coupled with strong up-slope effects from winds $>12-16 \mathrm{~m} \mathrm{~s}^{-1}$.

(c) A Puget Sound convergence zone created by 850 mbar level wind from the north-west $12-16 \mathrm{~m} \mathrm{~s}^{-1}$ or greater.

(d) The Jet Stream over Washington.

\section{$24 \mathrm{~h}$ PRECIPITATION AMOUNT}

$<7 \mathrm{~mm}$ WE - No frontal activity or dissipating weak frontal activity in a stable air mass with winds less than 10 knots at the pass level, or a weak upper disturbance passing mostly to the north or south of the State. Mostly cloudy conditions, could produce drizzle or light snow. Also weak afternoon convective showers in the spring could produce small precipitation amounts.

7-12 mm WE - Weak frontal activity during the $24 \mathrm{~h}$ period of forecast with weak up-slope following, or moderate front but precipitation split between two $24 \mathrm{~h}$ periods.

12-17 mm WE - Moderate frontal activity with moderate up-slope following, or strong front split between two $24 \mathrm{~h}$ periods.

17-25 mm WE - Moderate to strong frontal activity with only a short fetch between short waves or winds shifting and up-slope for short to medium duration.

25-37 mm WE - Strong front with medium duration upslope winds following frontal passage, usually associated with the Jet Stream over Washington.

37-75 mm (or greater) WE - Strong Jet Stream over Washington and strong up-slope winds of long duration and air mass of sub-tropical origin. 